REGARDS

SUR LEECONOMIE ALLEMANDE

BULLETIN ECONOMIQUE DU CRAC

\section{Regards sur l'économie allemande}

Bulletin économique du CIRAC

$73 \mid 2005$

Varia

\title{
Commerce : 1 entreprise sur 6 sur le marché de l'UE
}

Isabelle Bourgeois

\section{OpenEdition}

Journals

Édition électronique

URL : http://journals.openedition.org/rea/224

DOI : $10.4000 /$ rea. 224

ISBN : 978-2-8218-0842-3

ISSN : 1965-0787

Éditeur

CIRAC

Édition imprimée

Date de publication : 1 octobre 2005

Pagination : 37

ISSN : 1156-8992

Référence électronique

Isabelle Bourgeois, "Commerce : 1 entreprise sur 6 sur le marché de l'UE ", Regards sur l'économie allemande [En ligne], 73 | octobre 2005, document 1, mis en ligne le 06 juin 2008, consulté le 15 septembre 2020. URL : http://journals.openedition.org/rea/224

Ce document a été généré automatiquement le 15 septembre 2020.

(C) CIRAC 


\title{
Commerce : 1 entreprise sur 6 sur le marché de l'UE
}

\author{
Isabelle Bourgeois
}

\section{De plus en plus d'entreprises allemandes franchissent le Rhin}

1 Une entreprise allemande sur six se livre au commerce intra-communautaire, selon Destatis. Si la France reste la principale destination des biens et services allemands $(10,3 \%$ du total des exportations en 2004) et aussi le premier fournisseur (9,0\% des importations), les entreprises allemandes ont largement diversifié leurs échanges au sein d'un marché européen qui s'était étendu à l'est bien avant l'élargissement de l'UE (voir REA 63/03). Or la simplification des échanges et, plus encore, la sécurité juridique croissante au sein de l'espace communautaire amènent les entreprises à franchir de plus en plus volontiers le Rhin. La nouvelle transparence créée par l'instauration de la monnaie unique y a contribué elle aussi. Entre 2001 et 2004, le nombre des entreprises allemandes se livrant à l'import/export au sein de l'UE s'est ainsi accru de 17,5\%.

\section{Elles sont 470000 dans le commerce intra-UE}

Elles sont aujourd'hui 470 000. La moitié d'entre elles $(265000)$ se livre exclusivement à l'import, 115000 ont des activités mixtes, le restant $(90000)$ étant des spécialistes de l'export. Parmi ces dernières, 22000 ont réalisé un CA de plus de 1 million $€$. Sur les spécialistes de l'import, 21000 atteignaient le même résultat. Le nombre de celles réalisant un CA supérieur à 100 millions $€$ était respectivement de 500 et de 400 dans les deux types d'activité. Plus globalement, $56 \%$ du volume total des exportations sont à mettre à l'actif de... $0,2 \%$ seulement des entreprises, et $78 \%$ du volume des importations sont le fait de $1 \%$ des entreprises. Il y a là visiblement un effet de taille. Car si la pratique des échanges intracommunautaires est largement diffusée, elle exige 
aussi de la part des entreprises des compétences juridiques et, surtout, interculturelles, qui, pour des raisons de capacité financière, échappent encore trop largement aux PME.

\section{Le marché de l'UE est devenu leur espace naturel...}

Destatis se contente de publier des données brutes. Or elles masquent des réalités très diverses. La forte concentration du CA à l'export est à mettre au compte de deux catégories d'entreprises: d'un côté, la poignée de groupes industriels fortement internationalisés, de l'autre, l'existence de ces $20 \%$ de hidden champions parmi les PME (voir REA 69/04). Si on les trouve dans toutes les branches, elles se concentrent toutefois dans les plus globalisées, de la chimie à l'automobile en passant, bien sûr, par la branche-phare qu'est outre-Rhin la machine-outil. Le marché européen est leur espace naturel. Quant à la concentration du CA à l'import, elle en est le corollaire, l'Allemagne achetant à l'étranger les biens intermédiaires nécessaires à la confection des produits dont une large part est ensuite revendue ailleurs.

\section{... pour l'heure, dans l'industrie seulement}

La forte proportion d'entreprises impliquées dans le commerce intra-communautaire (une sur six) révèle aussi l'étroit degré d'interdépendance qu'atteignent aujourd'hui les économies des Etats membres de l'UE. Et on peut se demander plus généralement si, dans ces conditions, la stricte distinction entre import et export ne perd pas progressivement sa pertinence au sein d'un espace commun où la libre circulation des produits est assurée. A l'inverse des services, encore largement confinés dans les frontières nationales (voir REA 71/05). Or cet état constitue un handicap majeur pour cette industrie de services qui est au cœur de l'activité outre-Rhin. Cinq entreprises sur six restent encore à l'écart des échanges : parmi elles, celles qui offrent toute la gamme de services à l'industrie et ne peuvent guère les vendre hors d'Allemagne; et celles qui, malgré une forte demande, ne peuvent la satisfaire sur le marché européen. 